\title{
THE ROLE OF CARDIOPULMONARY BYPASS AND SURFACTANT IN PULMONARY DECOMPENSATION AFTER SURGERY FOR CONGENITAL HEART DISEASE
}

David A. Paul, MD, Jay S. Greenspan, MD, Deborah A. Davis, MD, Pierantonio Russo, MD, and Michael J. Antunes, MD, Newark and Wilmington, Del, and Philadelphia, Pa

Infants have been shown to have compromised lung function after cardiac operations. ${ }^{1}$ However, little is known about the specific effects of cardiopulmonary bypass (CPB) on the metabolism of endogenous pulmonary surfactant in infants undergoing an operation for congenital heart disease. The purpose of this study was to determine whether an alteration in endogenous pulmonary surfactant is, in part, responsible for the postoperative change in lung function observed in infants undergoing $\mathrm{CPB}$ during an operation for congenital heart disease.

\section{Methods}

Patient population. The study was approved by the Institutional Review Board at St Christopher's Hospital for Children and informed written consent was obtained. Fourteen infants with congenital heart disease undergoing both palliative and corrective procedures were enrolled in the study. The patients were divided according to the procedure performed: those infants undergoing cardiac procedures that required $\mathrm{CPB}(\mathrm{CPB}$ group; $\mathrm{n}=9$ ) and those infants undergoing cardiac procedures that did not require $\mathrm{CPB}$ (no $\mathrm{CPB}$ group; $\mathrm{n}=5$ ).

Operative care. Infants had standard monitoring of electrocardiogram, in-line blood presssure, transcutaneous oxyhemoglobin saturation, and end-tidal carbon dioxide concentration throughout the procedure. Anesthesia was induced with halothane then converted to a fentanyl technique. Extracorporeal circulation was performed with a membrane oxygenator (Cobe-VPC, Lakewood, Colo). Once full flow was achieved on $\mathrm{CPB}$, mechanical ventilation was terminated, and infants were maintained on endotracheal continuous positive airway pressure. Infants in the no CPB group received volume-limited, time-cycled ventilation throughout the procedures. Two patients in the $\mathrm{CPB}$ group underwent deep hypothermic circulatory arrest.

From the Department of Pediatrics, Section of Neonatology, Christiana Hospital, Newark, Del; Thomas Jefferson University School of Medicine, Philadalphia, Pa; The Nemours Cardiac Center, DuPont Hospital for Children, Wilmington, Del; and the Department of Cardiothoracic Surgery, St Christopher's Hospital for Children, Philadelphia, Pa.

Received for publication July 9, 1998; accepted for publication Dec 4, 1998

Address for reprints: David A. Paul, MD, Section of Neonatology, Christiana Hospital, 4755 Ogletown-Stanton Rd, Newark, DE 19718.

J Thorac Cardiovasc Surg 1999;117:1025-6

Copyright (C) 1999 by Mosby, Inc.

0022-5223/99 $\$ 8.00+0 \quad \mathbf{1 2 / 5 4 / 9 6 4 0 6}$
Pulmonary mechanics measurements. Dynamic pulmonary mechanics were determined by pneumotachometry and airway manometery (PeDS; MAS Inc, Hatfield, Pa). Sampling of pressure and flow signal occurred over a 30- to 60-second period. Signals for pressure, air flow, and volume were used to determine compliance of the respiratory system (CRS; milliliter c centimeter $\mathrm{H}_{2} \mathrm{O}^{-1}$. kilogram $^{-1}$ ) by least mean square analysis. Preoperative pulmonary function analysis was obtained in the operating room shortly after endotracheal intubation and the induction of anesthesia. Postoperative pulmonary function analysis was performed in the operating room or cardiac care unit within 1 hour after the completion of the operative procedure.

Tracheal aspirates. Tracheal lavage coincident with preoperative pulmonary function evaluation was performed in the operating room. Similarly, postoperative specimens were obtained in the operating room or cardiac care unit within 1 hour of completion of the operative procedure, immediately before the postoperative pulmonary function analysis. Lavage specimens were obtained by instilling $4 \mathrm{~mL}$ of saline solution into the endotracheal tube. The distal trachea was then suctioned into an in-line suction trap (Sherwood Medical, St Louis, Mo).

Protein and phospholipid determination. Total protein was measured by a modified Lowry method. To determine phospholipid concentration, aliquots of the lavage fluid were extracted with chloroform:methanol and analyzed for lipid phosphorus.

Data analysis. Parametric and nonparametric differences between each group were evaluated by the Student $t$ test or $\chi^{2}$. All data are expressed as the mean \pm SD.

Results. All infants tolerated the procedure for tracheal lavage and pulmonary function testing without difficulty. The differences between the groups in age, gestational age, weight, and gender were no more than expected by chance (Table I). Infants in the CPB group remained on CPB for 84 \pm 18.9 minutes.

CRS did not differ significantly before the operation between the 2 groups. However, CRS exhibited a decline from before to after the operation in those infants who required $\mathrm{CPB}$ as part of the operative procedure. There was no change in CRS from before to after the operation in the no CPB group (Table II).

Total phospholipids did not differ between the groups before the operation. Infants in the no CPB group demonstrated a postoperative rise in total phospholipids that approached statistical significance. Total phospholipids declined from before to after the operation in infants in the CPB group and 
Table I. Demographic data

\begin{tabular}{lccc}
\hline & $C P B(n=9)$ & $N o C P B(n=5)$ & $\mathrm{P}$ \\
\hline Age (mo) & $2.7 \pm 0.8$ & $2.7 \pm 1.4$ & .9 \\
Gestational age (wk) & $38.4 \pm 0.8$ & $38.8 \pm 1.2$ & .5 \\
Weight (kg) & $4.3 \pm 0.6$ & $4.0 \pm 0.7$ & .4 \\
Sex (M/F) & $4 / 5$ & $3 / 2$ & .6 \\
\hline
\end{tabular}

were lower after the operation when compared with the infants in the no CPB group. Similarly, the phospholipid/protein ratio exhibited a postoperative decline in the $\mathrm{CPB}$ group, and these infants had a lower postoperative phospholipid/protein when compared with infants in the no CPB group. The phospholipid/protein ratio did not change from before to after the operation in the no CPB group (Table II).

Discussion. Our data demonstrate a postoperative decline in total phospholipids and phospholipid/protein ratio in infants undergoing CPB during an operation for congenital heart disease. This decrease in phospholipids was associated with a drop in CRS. These data suggest that an increase in lung phospholipids may be important for overcoming operative lung injury. However, this response may be attenuated in infants undergoing bypass during an operation for congenital heart disease.

CPB has been shown to lead to an increase in pulmonary edema. ${ }^{2}$ Lung edema is accompanied by an increase in alveolar protein, which is a known inactivator of surfactant. ${ }^{3}$ Previous investigators have demonstrated an increase in capillary leak and alveolar protein after CPB. ${ }^{4}$ Along with a diminution in total phospholipids, the infants in our study who underwent CPB had a postoperative decline in the phospholipid/protein ratio, which may be indicative of lung injury and capillary leak. The changes in pulmonary surfactant demonstrated in the CPB group may be only partially responsible for the operative drop in CRS. Other factors including atelectasis and changes in pulmonary blood flow could also have contributed to the postoperative fall in CRS and changes in surfactant seen in the CPB group.

Our data support the findings of McGowan and colleagues, ${ }^{5}$ who demonstrated an alteration in surfactant composition in older infants and children after CPB. Furthermore, altered capillary permeability associated with $\mathrm{CPB}$ may accelerate pulmonary clearance of secreted surfactant. Because the postoperative specimens were obtained immediately after the operative procedure, it is unlikely that the increase in phospholipids in the no CPB group represented any increase in de novo surfactant synthesis. We speculate that the increase in total phospholipids seen in the no CPB
Table II. Pulmonary function and surfactant data

\begin{tabular}{|c|c|c|c|}
\hline & Preoperative & Postoperative & $\begin{array}{l}\mathrm{P} \text { (before } \\
\text { vs after) }\end{array}$ \\
\hline \multicolumn{4}{|l|}{ CRS } \\
\hline $\mathrm{CPB}$ & $0.94 \pm 0.12$ & $0.69 \pm 0.18$ & .01 \\
\hline No CPB & $0.71 \pm 0.39$ & $0.90 \pm 0.24$ & .38 \\
\hline$P(\mathrm{CPB}$ vs no $\mathrm{CPB})$ & .12 & .09 & \\
\hline \multicolumn{4}{|l|}{ Total phospholipids } \\
\hline $\mathrm{CPB}$ & $341 \pm 231$ & $132 \pm 141$ & .03 \\
\hline No CPB & $269 \pm 146$ & $648 \pm 421$ & .09 \\
\hline$P(\mathrm{CPB}$ vs no $\mathrm{CPB})$ & .54 & .01 & \\
\hline \multicolumn{4}{|l|}{ Phospholipid/protein } \\
\hline $\mathrm{CPB}$ & $0.17 \pm 0.11$ & $0.05 \pm 0.04$ & .01 \\
\hline No CPB & $0.21 \pm 0.17$ & $0.28 \pm 0.25$ & .62 \\
\hline$P(\mathrm{CPB}$ vs no $\mathrm{CPB})$ & .60 & .01 & \\
\hline
\end{tabular}

Preoperative and postoperative total phospholipids (micrograms per milliliter), phospholipid/protein ratio, and respiratory system CRS (milliliters centimeters $\mathrm{H}_{2} \mathrm{O}^{-1} \cdot$ kilogram $^{-1}$ ) in the infants in the CPB group and the infants in the no CPB group.

group resulted from ventilation-induced release of stored surfactant pools.

In summary, infants undergoing $\mathrm{CPB}$ during an operation for congenital heart disease have diminished total pulmonary phospholipids in the immediate postoperative period as compared with infants who do not require CPB. This decline in phospholipids is associated with a decrease in pulmonary compliance. Infants requiring CPB for surgical repair of congenital heart disease may have heightened pulmonary morbidity related to the alteration in surfactant metabolism. This suggests surfactant replenishment may be beneficial for some infants who require CPB.

\section{REFERENCES}

1. Greenspan JS, Davis DA, Russo PA, Wolfson MR, Shaffer TH. Operative creation of left or right cardiac shunts: Pulmonary functional sequelae. Ann Thorac Surg 1993;55:927-32.

2. Louagie Y, Gonzalez E, Jamart J, Bulliard G, Schoevaerdts JC. Postcardiopulmonary bypass lung edema: a preventable complication. Chest 1993;103:86-95.

3. Ikegami M, Jobe A, Berry D. A protein that inhibits surfactant in respiratory distress syndrome. Biol Neonate 1993;50:121-9.

4. Kirklin JK. Prospects for understanding and eliminating the deleterious effects of cardiopulmonary bypass. Ann Thorac Surg 1991;51:529-31.

5. McGowan FX, Ikegami M, del Nido PJ, Motoyama EK, Kurland G, Davis PJ, et al. Cardiopulmonary bypass significantly reduces surfactant activity in children. J Thorac Cardiovasc Surg 1993; 106:968-77. 